\title{
ORIGINAL ARTICLE Functional interplay between MDM2, p63/p73 and mutant p53
}

\author{
MH Stindt ${ }^{1,3}$, PAJ Muller ${ }^{1,3,4}$, RL Ludwig $^{1}$, S Kehrloesser ${ }^{2}$, V Dötsch ${ }^{2}$ and KH Vousden ${ }^{1}$
}

\begin{abstract}
Many cancers express mutant p53 proteins that have lost wild-type tumor suppressor activity and, in many cases, have acquired oncogenic functions that can contribute to tumor progression. These activities of mutant p53 reflect interactions with several other proteins, including the $\mathrm{p} 53$ family members $\mathrm{p} 63$ and p73. Mutations in $\mathrm{p} 53$ that affect protein conformation (such as R175H) show strong binding to p63 and p73, whereas p53 mutants that only mildly affect the conformation (such as R273H) bind less well. A previously described aggregation domain of mutant p53 is not required for p63 or p73 binding; indeed, mutations within this region lead to the acquisition of a mutant p53 phenotype-including a conformational shift, p63/p73 binding and the ability to promote invasion. The activity of wild-type p53 is regulated by an interaction with MDM2 and we have investigated the potential role of MDM2 in the mutant p53/p63/p73 interactions. Both mutant p53 and p73 bind MDM2 well, whereas p63 binds much more weakly. We found that MDM2 can inhibit p63 binding to p53R175H but enhances the weaker p53R273H/p73 interaction. These effects on the interactions are reflected in an ability of MDM2 to relieve the inhibition of p63 by $\mathrm{p} 53 \mathrm{R} 175 \mathrm{H}$, but enhance the inhibition of $\mathrm{p} 73$ activity by $\mathrm{p} 53 \mathrm{R} 175 \mathrm{H}$ and $\mathrm{R} 273 \mathrm{H}$. We propose a model in which MDM2 competes with p63 for binding to $\mathrm{p} 53 \mathrm{R} 175 \mathrm{H}$ to restore $\mathrm{p} 63$ activity, but forms a trimeric complex with $\mathrm{p} 73$ and $\mathrm{p} 53 \mathrm{R} 273 \mathrm{H}$ to more strongly inhibit p73 function.
\end{abstract}

Oncogene (2015) 34, 4300-4310; doi:10.1038/onc.2014.359; published online 24 November 2014

\section{INTRODUCTION}

p53 is an important tumor suppressor protein that functions as a transcription factor, binding DNA sequences in the promoters of a large number of target genes that mediate responses such as cell cycle arrest, senescence and apoptosis. ${ }^{1}$ p53 is altered in the majority of human cancers, frequently resulting in the expression of mutant p53 proteins with single amino-acid substitutions in the DNA-binding domain (DBD). ${ }^{2}$ In general, these mutant $\mathrm{p} 53 \mathrm{~s}$ have lost the ability to bind the p53 binding sites in DNA and so fail to exhibit the wild-type p53 tumor suppressor activity. ${ }^{3}$ Furthermore, many of the mutant p53 proteins have also been shown to acquire a gain of function that can contribute to all stages of tumorigenesis, including the ability to promote invasion and metastasis. ${ }^{4,5}$

p53 belongs to a family of related proteins, which also includes p63 and p73., Each of the family members is expressed as a number of isoforms, including $\mathrm{N}$-terminal variants that encode either a full-length (TA) or truncated $(\Delta N)$ p53, p63 and p73., Alternative splicing in the $C$ terminus of each protein can further give rise to a multitude of $C$-terminal isoforms such as $a, \beta$ or $\gamma$. ${ }^{9}$ Regulation of the p53 family members depends on various homoand heteromeric interactions. Each of the p53 family members contains a C-terminal oligomerization domain, allowing the formation of homotetramers to allow sequence-specific DNA binding required to function as a transcription factor. ${ }^{10,11}$ The extreme $C$ terminus of p63, present in TAp63a, contains a transactivation inhibitory domain that can interact with the $\mathrm{N}$-terminal domain of the protein, resulting in the adoption of a closed inactive dimer. ${ }^{12}$ The TAp63a can therefore switch between an inactive dimer and an active tetramer, ${ }^{13}$ a level of control that is not seen for TAp73a. ${ }^{14}$ Although p63 and p73 can also form heterotetramers through the oligomerization domain, this region of p53 is unable to interact with p63 or p73. ${ }^{15,16}$ However, cancerassociated point mutations within the DBD of p53 can both change the conformation of the p53 protein and allow the interaction of mutant p53 with p63 and p73. ${ }^{17-21}$ This interaction of mutant p53 with p63/p73 can inhibit the transcriptional activity of p63/p73 and promote invasion. ${ }^{22-24}$ Interestingly, the interaction between mutant $\mathrm{p} 53$ and $\mathrm{p} 63$ or p73 can be influenced by many proteins such as TOPBP1, Pin1, ANKRD11 and SMAD2 with functional consequences for p63 and p73 transcriptional function. ${ }^{5}$

Another important regulator of $\mathrm{p} 53$ is $\mathrm{MDM} 2$, one of the principal ubiquitin ligases responsible for targeting p53 for degradation. ${ }^{25,26}$ The interaction between $\mathrm{N}$-terminal domains in both MDM2 and p53 allows for the ubiquitination and degradation of p53, although E3 ligase-defective MDM2 mutants can retain the ability to inhibit p53 function through this interaction, which obscures the $\mathrm{N}$-terminal transcriptional activation domain of $p 53 .^{27,28}$ MDM2 can also form an interaction with p73, ${ }^{29-31}$ although this does not lead to the ubiquitination and degradation of p73. By contrast, an MDM2/p63 interaction is seen in some $\mathrm{e}^{32,33}$ but not all studies. ${ }^{34,35}$

In this study, we examined the interactions between the p53 family members and MDM2. We confirmed that while mutant p53 can bind to both p63 and p73, MDM2 preferentially binds to $\mathrm{p} 73$. This differential binding had a clear impact on the binding of mutant p53 to p63 or p73, with opposite functional consequences on the transcription activity of p63 or p73.

\section{RESULTS}

Binding of p63 and p73 to mutant p53

Both p63 and p73 have been shown to interact with mutant p53 to varying extents, depending on the nature of the p53

${ }^{1}$ Cancer Research UK Beatson Institute, Glasgow, UK and ${ }^{2}$ University of Frankfurt, Frankfurt, Germany. Correspondence: Professor KH Vousden, Cancer Research UK Beatson Institute, Garscube Estate, Switchback Road, Bearsden, Glasgow G61 1BD, UK.

E-mail: k.vousden@beatson.gla.ac.uk

${ }^{3}$ These authors contributed equally to this work.

${ }^{4}$ Current address: MRC Toxicology Unit, Leicester, UK.

Received 2 April 2014; revised 4 September 2014; accepted 14 September 2014; published online 24 November 2014 
mutation. ${ }^{17-20}$ We confirmed previous observations that $\mathrm{p} 53 \mathrm{R} 175 \mathrm{H}$, a conformational mutant that results in misfolding of the p53 protein, ${ }^{36}$ binds much more strongly to both N-terminal isoforms of p63a (TA and $\Delta N$ ) and p73a (TA and $\Delta N$ ) than p53R273H, which directly affects a DNA-contacting residue in p53, but only slightly perturbs the wild-type conformation of the protein (Figure 1a). ${ }^{17-20}$ Consistent with these reports, we observed similar binding of the TA and $\Delta N$ versions of p63 and p73 to p53R175H under conditions used for all the subsequent experiments in this study.

As $\mathrm{p} 53 \mathrm{R} 175 \mathrm{H}$ was the better binding partner, we used this mutant to investigate which domains in p63 and p73 were required to interact with mutant $p 53$. Previous studies have shown that the DBD of $p 53$ is required for the interaction of mutant $p 53$ with p63 or p73. ${ }^{19,20}$ Interestingly, while deletion of the DBD of TAp73a $(\Delta 131-307)$ or $\Delta \mathrm{Np73a}(\Delta 82-258)$ reduced the interaction with $\mathrm{p} 53 \mathrm{R} 175 \mathrm{H}$, deletion of this domain in TAp63a $(\Delta 138-319)$ or $\Delta$ Np63a $(\Delta 84-265)$ somewhat enhanced binding (Figures $1 \mathrm{~b}$ and $\mathrm{c}$ and see below). The contribution of the DBD of TAp73a to the interaction with mutant $\mathrm{p} 53$ was confirmed in a reciprocal immunoprecipitation of p73 (using a hemagglutinin (HA) antibody) to identify co-precipitating p53R175H (Supplementary Figure S1A). However, although deletion of the DBD of p73a reduced binding to $\mathrm{p} 53$, we consistently saw that this interaction was not completely abolished by this deletion. We therefore explored further the possibility that binding of $\mathrm{p} 53 \mathrm{R} 175 \mathrm{H}$ involved regions distinct from the DBD in both p63 and p73.

As both $\Delta \mathrm{Np} 63$ and $\triangle \mathrm{Np} 73$ retained $\mathrm{p} 53 \mathrm{R} 175 \mathrm{H}$ binding (Figure 1a), suggesting that the $\mathrm{N}$ terminus was not necessary for the interaction, we examined the contribution of the $C$ terminus of each protein using deletion mutants and the C-terminal truncated isoforms (Figure 1c). In the case of p63, the shorter isoforms TAp63 $\beta$ and TAp63 $\gamma$ were consistently expressed at lower levels compared with TAp63a (Figure 1d), an observation previously noted with other TAp63a proteins mutated in the transactivation inhibitory domain. ${ }^{12}$ However, we consistently found that both TAp63 $\beta$ and TAp63 $\gamma$ were significantly impaired for $\mathrm{p} 53 \mathrm{R} 175 \mathrm{H}$ binding compared with TAp63a (Figure 1, long exposure and Supplementary Figure S1B). Analysis of further TAp63a mutants indicated that deletion of amino acids 462-561 also perturbed the interaction with p53R175H (Figure 1d and Supplementary Figures $1 \mathrm{c}$ and d).

During the course of these studies, we noted that removal of the DBD of TAp63a led to somewhat increased binding to p53R175H (Figure 1d and Supplementary Figure S1C). Previous studies have shown that TAp63a can be held in an inactive compact dimer through an interaction between the $\mathrm{C}$ - and $\mathrm{N}$-terminal domains of the protein, ${ }^{13,37}$ and we considered that removal of the entire DBD may prevent this intramolecular interaction and inhibit the formation of closed dimers. To test directly the effect of inhibiting the dimer formation in TAp63a, we used a mutant within the $\mathrm{N}$ terminus of TAp63a (TAp63aFWL) that creates an open and tetrameric state that is also transcriptionally inactive. ${ }^{13}$ Interestingly, this mutant also showed enhanced p53R175H binding (Supplementary Figure S1D), supporting the suggestion that mutant p53 binds preferentially to the tetrameric form of TAp63.

Turning to TAp73, we noted that TAp73 $\beta$ clearly showed loss of binding to $\mathrm{p} 53 \mathrm{R} 175 \mathrm{H}$ (Figure 1e), indicating that similar to p63, the $C$ terminus of $p 73$ has a role in mediating this interaction. Surprisingly, however, TAp73y regained the ability to bind to p53R175H (Figure 1e). Despite the loss of the C-terminal sequences present in TAp73a, TAp73 $\gamma$ contains 77 additional unique amino acids at the $C$ terminus (Figure $1 c$ ), which appear to confer binding competence.
A previously proposed aggregation domain of mutant p53 is not required to bind p63 or promote invasion

Although p63 and p73 can form mixed tetramers through their C-terminal tetramerization domains, ${ }^{15}$ the interaction of mutant $\mathrm{p} 53$ with p63/p73 has been shown to depend on the DBD of mutant p53. ${ }^{19,20}$ While examining the effects of small deletions in the DBD of $\mathrm{p} 53$, which would be expected to destabilize $\mathrm{p} 53$, we found that the binding of p53R175H $\Delta 251-312$ to TAp63a appeared somewhat reduced (Figure 2a), although this was less apparent when looking at the p53R175H $\Delta 251-312$ interaction with TAp73a (Figure 2b). This observation was of interest in light of a recent publication reporting the formation of aggregates by mutant p53 that can include p63 and $p 73 .^{38}$ This study identified an aggregation domain within mutant p53 spanning residues $251-258$, with an absolute requirement for isoleucine 254 . We therefore sought to determine whether aggregation was necessary for $\mathrm{p} 53$ to bind $\mathrm{p} 63$ or $\mathrm{p} 73$. A mutant in which the complete aggregation domain had been removed $(\mathrm{R} 175 \mathrm{H}$ $\Delta 251-257$ ) still showed interaction with TAp63a (Figure 2a) and TAp73a (Figure 2b), although we considered that this may reflect a misfolding of the protein caused by the partial deletion of the domain. Surprisingly, however, even the point mutation I254R that has previously been shown to prevent aggregation ${ }^{38}$ did not inhibit binding of the $\mathrm{R} 175 \mathrm{H}$ p53 mutant to p63 or p73 in our hands (Figures $2 \mathrm{a}$ and b). Furthermore, introduction of the I254R point mutant alone into p53 (without the $\mathrm{R} 175 \mathrm{H}$ mutation) induced enhanced binding to TAp63a to a similar extent as $\mathrm{R} 175 \mathrm{H}$, under conditions where DNA contact mutants such as R273H or R248W showed very low binding (Figure 2c). The efficiency of mutant p53 binding to $\mathrm{p} 63$ and p73 correlated with a misfolded conformation of the p53 protein, as assessed by a change in reactivity to antibodies 1620 (which recognizes folded wild-type p53) and 240 (which recognizes misfolded p53 associated with mutations such as $\mathrm{R} 175 \mathrm{H}$, which cause structural instability of the p53 protein). ${ }^{39}$ Using this approach, we found that, similar to $\mathrm{R} 175 \mathrm{H}$, introduction of the $\mathrm{I} 254 \mathrm{R}$ mutation resulted in clear misfolding of $\mathrm{p53}$, which correlated with the acquisition of reactivity with Ab240 and TAp63a or TAp73a binding (Figures $2 \mathrm{c}-\mathrm{e}$ ). Although these results differ somewhat from those previously published, ${ }^{38}$ it is well established that even wildtype p53 is structurally very unstable, ${ }^{40}$ and small differences in extraction procedures may result in differences in the extent of unfolding of p53 proteins. ${ }^{41}$ To assess the functional consequence of the I254R mutation, we examined whether this aggregation mutant acquired the gain of function that is characteristic of mutant $\mathrm{p} 53 \mathrm{~s}$ in cells. Several studies have shown that mutant p53s (such as R175H and $\mathrm{R} 273 \mathrm{H}$ ) can promote the invasive behavior of p53-null cells in Matrigel invasion assays ${ }^{22,23}$ and that this correlates with the ability to inactivate TAp63a. Interestingly, a p53 protein carrying only the I254R mutation promoted invasion in this assay as efficiently as a series of tumor-derived p53 mutants that have previously been shown to acquire this gain of function (Figure $2 f$ ) and was similarly able to inhibit TAp63a transcriptional activity (Supplementary Figure 1E). Taken together, these results suggest that mutations in p53 that have been reported by others to prevent aggregation do not necessarily impede the acquisition of p63-binding activity or the ability to promote invasive behavior in cells.

\section{MDM2 binds p73 more strongly than p63}

MDM2 is a key regulator of p53 activity, and functions through various mechanisms to inhibit $\mathrm{p} 53$. Previous studies have shown that MDM2 also binds p73, but interacts much more weakly, if at all, with p63. ${ }^{34,42}$ We were also able to confirm that MDM2 bound well to TAp73a, TAp73y and $\triangle \mathrm{Np73a}$ (Figure $3 \mathrm{a}$ and Supplementary Figure 1F), but showed a much weaker ability to interact with either TAp63a or $\Delta \mathrm{Np} 63 \mathrm{a}$, using the same antibody and similar immunoprecipitation conditions as for the p73 isoforms (Figure 3a). The principal binding site for $\mathrm{p} 53$ on MDM2 is within the N-terminal binding pocket on MDM2, which 
a
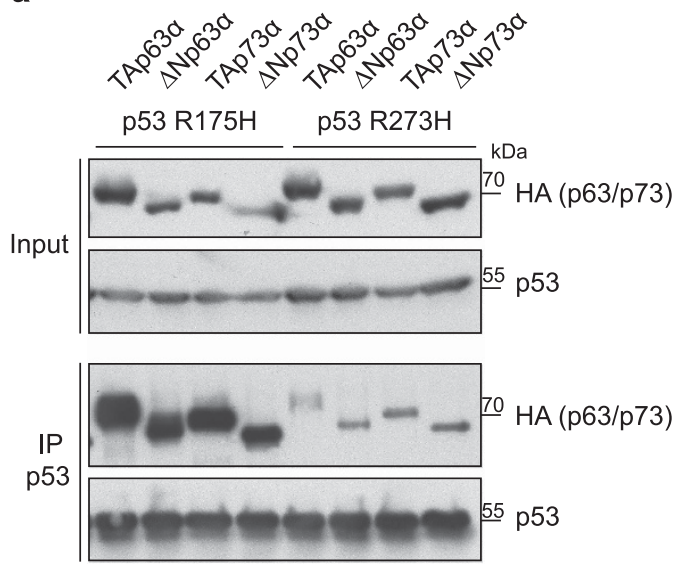

b

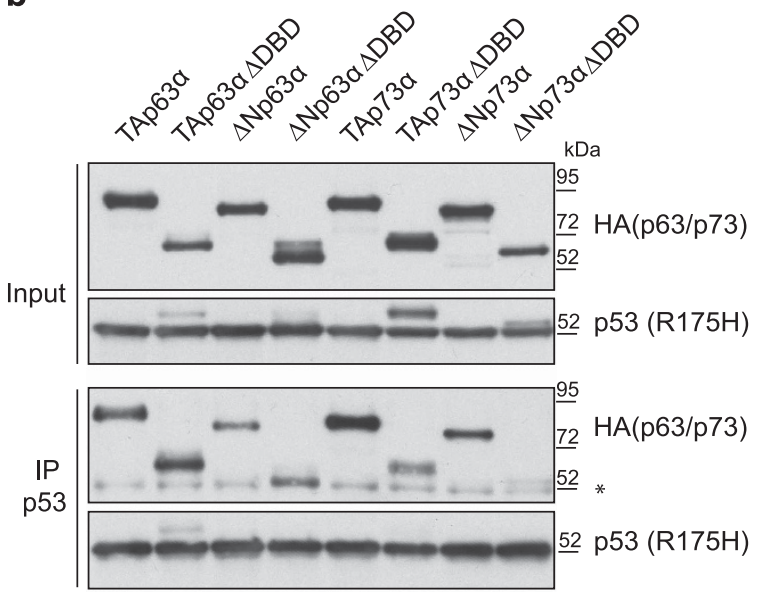

C

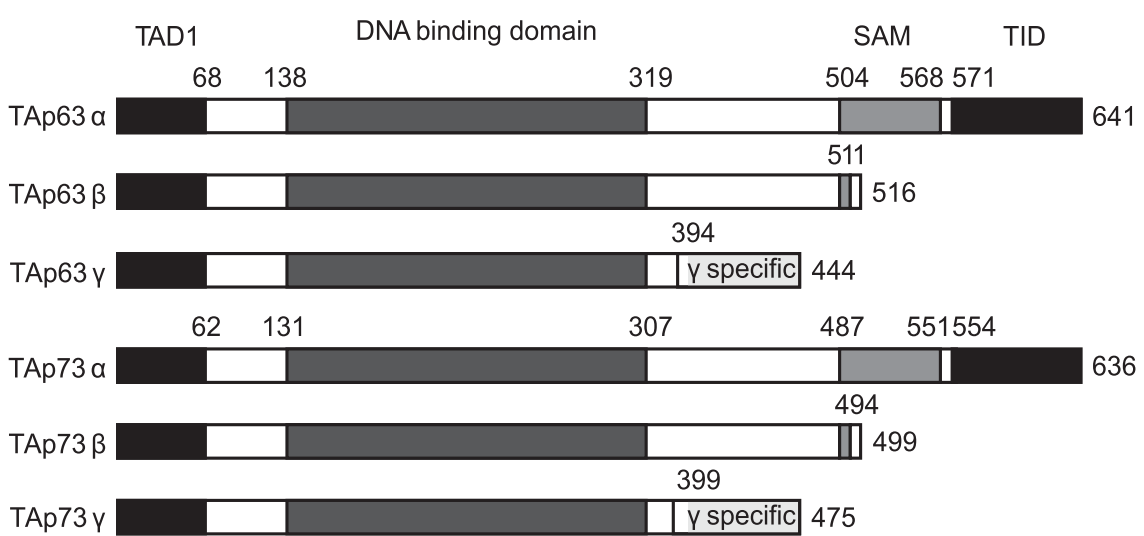
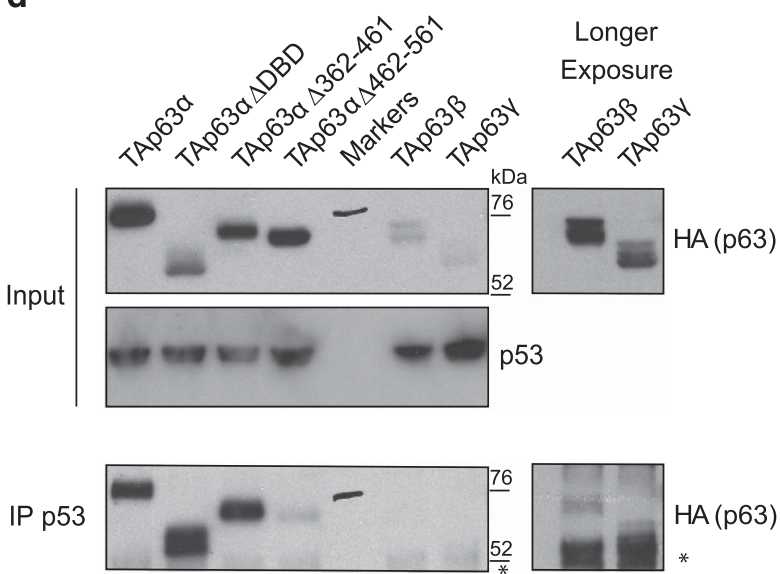
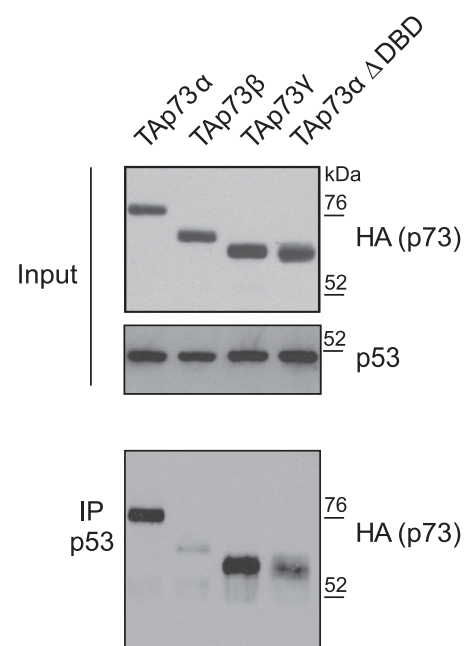

Figure 1. Mutant p53 interaction with p63 and p73. (a) Immunoprecipitation (IP) of p53 with DO-1 from HCT116 p53-/- cells transfected with $3 \mu \mathrm{g}$ HA-tagged TAp63 $\alpha, \Delta \mathrm{Np} 63 \alpha$, TAp73 $\alpha$ or $\Delta \mathrm{Np} 73 \alpha$ in combination with $2 \mu \mathrm{g}$ mutant p53 (R175H or R273H). Input and immunoprecipitated p53, p63 and p73 levels were determined by western blot using DO- 1 and HA antibodies. (b) IP of p53 with DO-1 from HCT116 p53 - / - cells transfected with $3 \mu \mathrm{g} \mathrm{HA}$-tagged TAp63 $\alpha$, TAp63 $\alpha \Delta$ DBD, $\Delta$ Np63 $\alpha, \Delta$ Np63 $\alpha \Delta$ DBD, TAp73 $\alpha$, TAp73 $\alpha \Delta$ DBD, $\Delta$ Np73 $\alpha$ or $\Delta \mathrm{Np} 73 \alpha \Delta \mathrm{DBD}$ in combination with $2 \mu \mathrm{g}$ p53R175H. Input and immunoprecipitated p53, p63 and p73 levels were determined by western blot using DO-1 and HA antibodies. *A nonspecific band seen in all IPs. (c) Schematic representation of TAp63 $\alpha$, TAp63 $\beta$, TAp63 $\gamma$, TAp73 $\alpha$, TAp73 $\beta$ and TAp73 $\gamma$, showing the major functional domains: transactivation domain 1 (TAD1), DBD, sterile $\alpha$ motif (SAM) domain and transactivation inhibitory domain (TID). Also indicated is the $\gamma$-specific region. Not to scale. (d) IP of p53 with DO- 1 from HCT116 p53-/ - cells transfected with $2 \mu \mathrm{g}$ HA-tagged TAp63 $\alpha$, TAp63 $\alpha \Delta$ DBD, TAp63 $\alpha \Delta 362-461$, TAp63 $\alpha \Delta 462-561$ (LHS), TAp63 $\beta$ or TAp63 $\gamma$ (RHS) with $1.5 \mu g$ mutant p53 $(\mathrm{R} 175 \mathrm{H})$. Input for $\mathrm{p} 53$ and input and co-precipitated p63 was detected by western blotting with DO- 1 and HA antibodies. A longer exposure of the last two lanes is shown to the RHS. *A nonspecific band in all IPs also seen in (b). (e) IP of mutant p53 with DO-1. HCT116 p53 - / - cells were transfected with $0.75 \mu \mathrm{g}$ HA-tagged TAp73 $\alpha$, TAp73 $\beta$, TAp73 $\gamma$ or TAp73 $\alpha \Delta$ DBD and $1.5 \mu \mathrm{g}$ mutant p53 (R175H). Input for p53 and input and co-precipitated p73 was detected by western blotting with DO-1 and HA antibodies. 
a
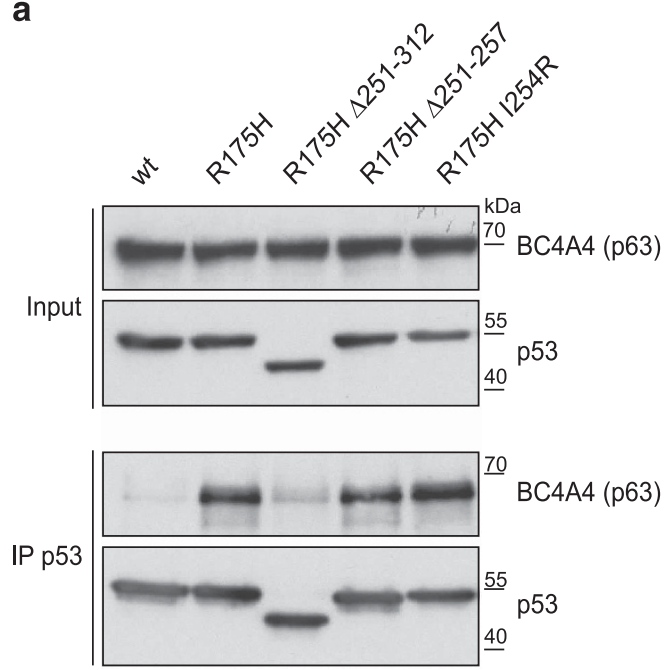

C
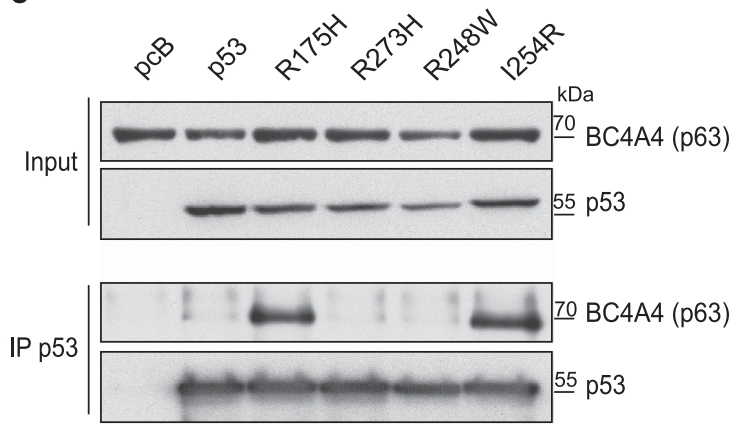

b
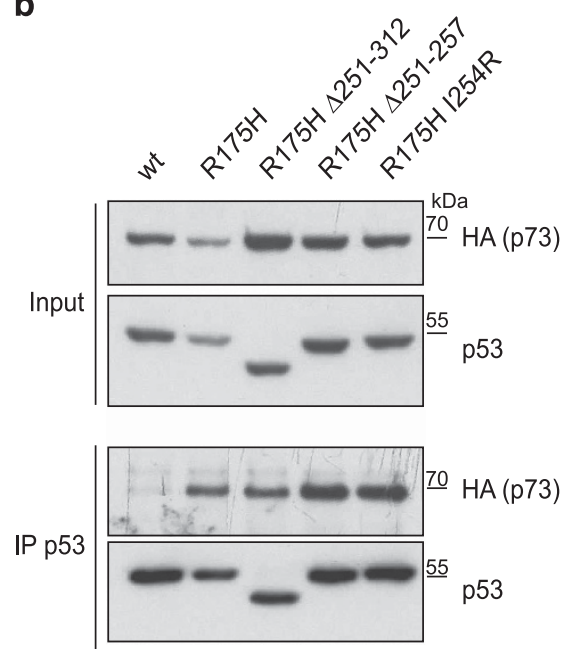

d

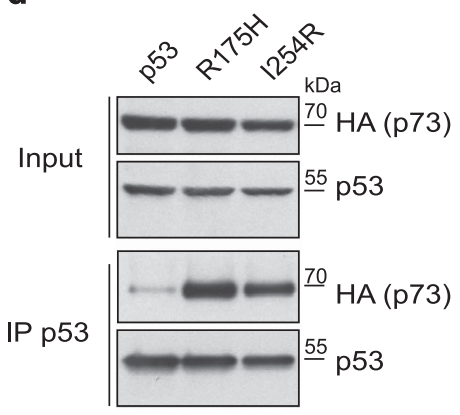

e
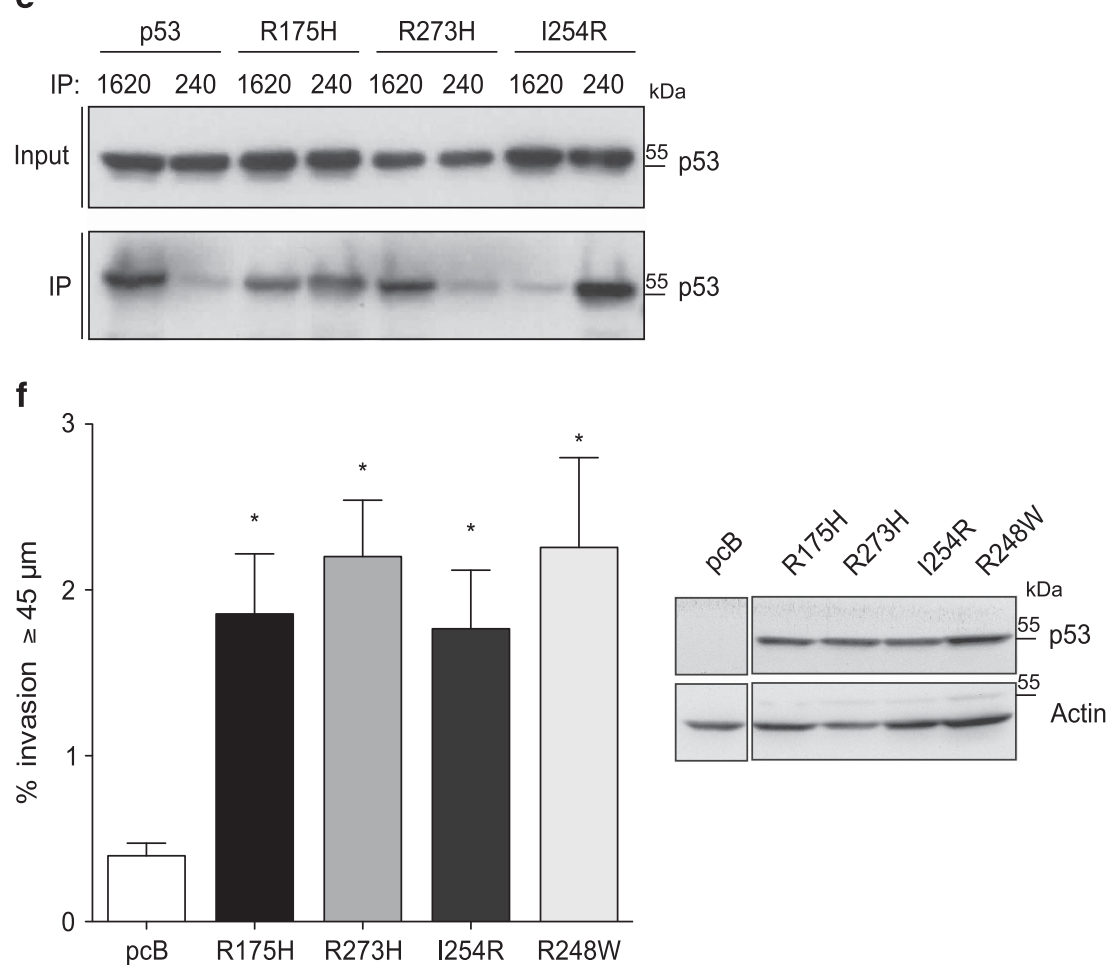

Figure 2. For caption please see next page. 
is disrupted by deleting residues $58-89$. Interestingly, loss of this region did not reduce the binding of MDM2 to TAp73 or $\triangle N p 73 a$ (Figure $3 b$ ), suggesting that $p 73$ and $p 53$ bind to different regions on MDM2. Although MDM2 controls p53 to a large extent through ubiquitination and degradation, interaction with MDM2 can also directly inhibit the transcriptional activity of p53, as seen by the effect of coexpression of an MDM2 mutant that lacks E3 ligase activity (MDM2 C464A) with p53 (Figure 3c). MDM2 does not target p73 for degradation, ${ }^{29}$ but the E3 mutant MDM2 C464A also inhibited the transcriptional activity of TAp73a and TAp73 $\gamma$ (Figure 3d). However, coexpression of this MDM2 mutant did not significantly affect the transcriptional activity of either TAp63a or TAp63y (Figure 3d), consistent with the much weaker binding of MDM2 to TAp63. We note that, as shown previously, TAp63a shows relatively weak transcriptional activity in these assays, ${ }^{6,37}$ most likely reflecting the adoption of the closed dimeric and therefore inactive conformation of this transfected protein. ${ }^{13}$

Having established that TAp73a forms an interaction with both p53R175H and MDM2, whereas TAp63a bound p53R175H well but MDM2 only very weakly, we examined the effect of MDM2 expression on the mutant p53/p63 or p73 interaction. Intriguingly, the interaction of mutant p53 (either R175H or 1254R) with TAp63a was substantially reduced following coexpression of an E3-inactive MDM2 without apparently affecting the weak interaction of p53R273H or wild-type p53 to TAp63a in HCT116 - / - cells (which have lost full-length p53 expression but retain the expression of some N-terminally truncated p53 isoforms) (Figure 4a) or H1299 cells (which are null for all forms of p53) (Supplementary Figure 2A). Overexpression of MDM2 C464A in BXPC3 cells expressing p53Y220C (a conformational mutant) (Figure 4b) or SKBR3 cells expressing p53R175H (Supplementary Figure 2B) further demonstrated a decrease in the binding capacity of endogenous mutant p53 to endogenous p63 (most likely the TAp63a variant based on size) in the presence of MDM2. Consistent with these observations, titrating MDM2 expression resulted in a dose-dependent decrease in the interaction between $\mathrm{p} 53 \mathrm{R} 175 \mathrm{H}$ and TAp63a, indicating that MDM2 competes with TAp63a for binding to mutant p53 (Figure 4c).

In contrast to the behavior of p63, coexpression of MDM2 C464A did not clearly affect the binding of R175H or I254R to TAp73a or $\triangle \mathrm{Np73a}$ and markedly enhanced the interaction of these p73 isoforms with p53R273H in HCT116-/- cells (Figures 4d and e) or $\mathrm{H} 1299$ cells (Supplementary Figure 2C). In these assays, MDM2 even promoted an interaction between wildtype p53 and TAp73a or $\Delta$ Np73a (Figure $4 \mathrm{e}$ and Supplementary Figure 2C). However, immunoprecipitation of the complex through MDM2 instead of p53 showed that while p53R273H bound $M D M 2$, it did not increase the binding between MDM2 and TAp73a, compared with the interaction seen in the absence of mutant p53 (Supplementary Figure 2D). These data suggest that
MDM2 facilitates the binding of TAp73a to p53R273H, but that p53R273H does not govern the interaction between MDM2 and TAp73a. An increase in binding of p53R248W (in HCT116 cells) and p53R273H (in U251 cells) to p73 (most likely TAp73a based on size) following MDM2 expression demonstrated that the effect of MDM2 is also apparent with endogenously expressed mutant p53 and TAp73a (Figure $4 \mathrm{f}$ and Supplementary Figure 2E). Importantly, the ability of MDM2 to enhance the p53R273H/p73 interaction was dependent on the N-terminal MDM2-binding domain on $\mathrm{p} 53$, as shown by a p53 protein deleted for this domain $(\Delta \mathrm{l})$. The p53 $\Delta \mathrm{l}$ protein did not co-precipitate MDM2 (as expected) and did not gain the ability to interact with $\triangle N p 73 a$ in the presence of MDM2 (Figure 4e). As MDM2 can bind both mutant p53 and TA/ $\triangle N p 73 a$, these results indicate that $\mathrm{p} 53 / \mathrm{MDM} 2 / \mathrm{p} 73 a$ can form a trimeric complex, and that the p53/TAp73a or p53/ $\mathrm{Np} 73 a$ interaction is enhanced by MDM2.

Various reports show that mutant p53s can be stabilized by chaperones that impair MDM2-mediated degradation of $\mathrm{p53}$. $^{43,44}$ Furthermore, heat-shock protein 70 (HSP70) can have a role in stabilizing the $\mathrm{p} 53 \mathrm{R} 175 \mathrm{H} / \mathrm{TAp} 73 \mathrm{a}$ interaction and destabilizing the p53R175H/TAp63a interaction, ${ }^{45}$ suggesting that there may be a similarity to our observations with MDM2. However, under our experimental conditions, HSP70 did not alter the R175H/TAp63a or $\mathrm{R} 175 \mathrm{H} / \mathrm{TAp} 73 \mathrm{a}$ interaction (Supplementary Figures $3 \mathrm{~A}$ and $\mathrm{B}$ ), indicating that the effect of MDM2 on these interactions is not mediated entirely through HSP70.

To test the consequences of the different effects of MDM2 on the interaction of mutant p53 with p63 and p73, we looked at the impact on TAp63a/ $/ \mathrm{T}$ and TAp73a/ $Y$ transcriptional activity (Figure 5a). As expected, expression of p53R175H reduced the transcriptional activity of TAp63a, but not TAp63y (Figure 5a), reflecting the capacity of mutant p53 to interact with the different p63 isoforms (Figures 1d and 5a). Interestingly, titration of increasing amounts of MDM2, which was shown to dissociate binding of $\mathrm{p} 53 \mathrm{R} 175 \mathrm{H}$ to TAp63a (Figure 4a), significantly alleviated the inhibition of $\mathrm{p} 53 \mathrm{R} 175 \mathrm{H}$ on TAp63a, while having no effect on TAp63y (Figure 5a). In contrast, p53R175H inhibited the transcriptional activity of both TAp73a and TAp73y (reflecting the ability to bind both isoforms; Figure 1) and a titration of MDM2 even slightly increased this inhibition (Figure 5a), correlating with the formation of the mutant p53/TAp73a/MDM2 complex (Figure 4b). Previous studies have shown that p53R273H can inhibit the transcriptional activity of TAp73a, despite showing only weak binding. ${ }^{23}$ Additional expression of MDM2 further decreased TAp73a luciferase activity (Supplementary Figure 3C), consistent with the concurrent binding of p53R273H, TAp73a and MDM2.

Taken together, these results show that the binding of mutant p53 to TAp63a and TAp73a is differentially modulated by MDM2, which attenuates mutant p53 binding and inhibition of TAp63a,

Figure 2. The aggregation domain in p53 is not required for p63/p73 binding or the ability to promote invasion. (a) Immunoprecipitation of p53 with DO-1 in HCT116 p53 - / - cells transfected with $3 \mu \mathrm{g}$ TAp63 $\alpha$ in combination with $3 \mu \mathrm{g} \mathrm{p53wt,} \mathrm{p53R175H,} \mathrm{p53R175H} \Delta 251-312$, p53R175H $\Delta 251-257$ or p53R175H I254R. p53 and p63 expression was determined in the inputs and in precipitated material by western blot using DO-1 and BC464 (p63) antibodies. (b) Immunoprecipitation of p53 with DO-1 in HCT116 p53 - / - cells transfected with $3 \mu$ HA-tagged TAp73 $\alpha$ in combination with $3 \mu \mathrm{g}$ p53wt, p53R175H, p53R175H $\Delta 251-312, \mathrm{p} 53 \mathrm{R} 175 \mathrm{H} \Delta 251-257$ or p53R175H I254R. p53 and p73 expression was determined in the inputs and in precipitated material by western blot using DO- 1 and HA antibodies. (c) Immunoprecipitation of p53 with DO-1 in HCT116 p53-/ - cells transfected with $3 \mu \mathrm{g}$ TAp63 $\alpha$ in combination with $2 \mu \mathrm{g}$ p53wt, p53R175H, p53R273H, p53R248W or p531254R p53 and p63 expression was determined in the inputs and in precipitated material by western blot using DO-1 and BC464 (p63) antibodies. (d) Immunoprecipitation of p53 in HCT116 p53 - / - cells transfected with $3 \mu \mathrm{g}$ HA-tagged TAp73 $\alpha$ in combination with $3 \mu \mathrm{g}$ p53wt, p53R175H or p53/254R. p53 and p73 expression was determined in the inputs and in precipitated material by western blot using DO-1 and HA

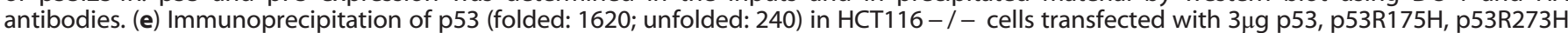
or p531254R. p53 expression was determined in the inputs and in precipitated material by western blot using a DO-1 antibody. (f) H1299 cells were retrovirally infected with an empty vector or the indicated p53 mutants (in a pWZL blast vector). Blasticidin-resistant cells were selected and their invasion towards hepatocyte growth factor (HGF) over $72 \mathrm{~h}$ was measured in inverted transwell invasion assays. Bars represent the mean of invasion beyond $45 \mu \mathrm{m}$ in four sets of triplicates. Error bars as standard error of the mean. ${ }^{*} \mathrm{~A} P$-value $<0.02$ compared with the empty vector-expressing cells. The expression of the constructs is shown by western blot and actin was used as a loading control (right). Panels form part of the same gel. 
a
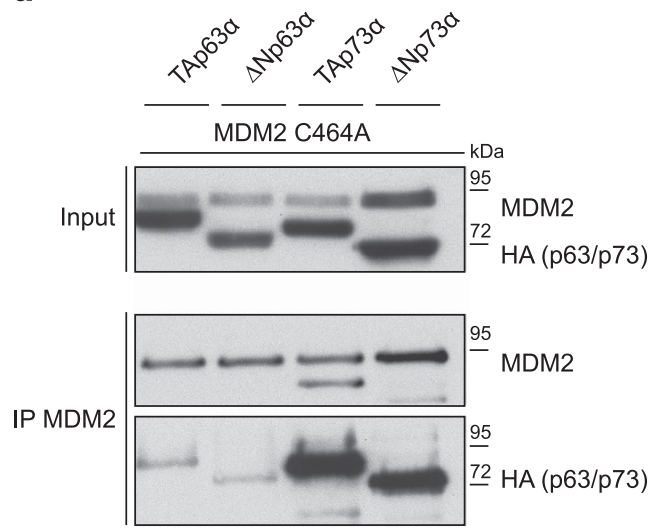

C

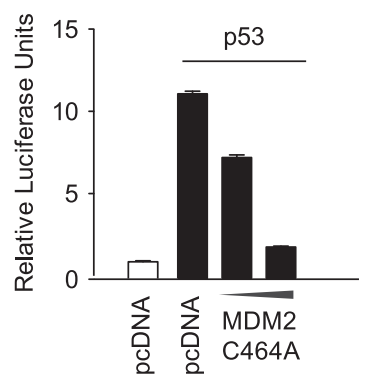

p53

pcDNA MDM2 C464A

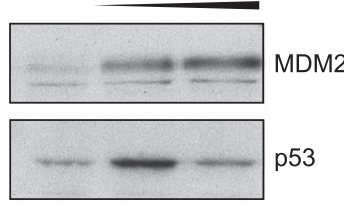

d b

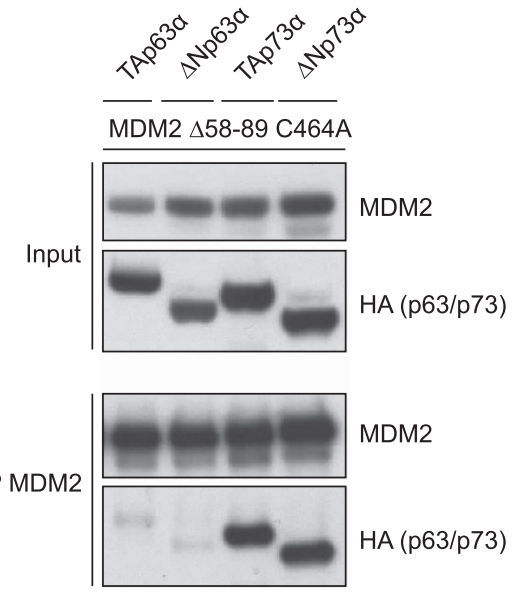

BPAG-1 Luciferase
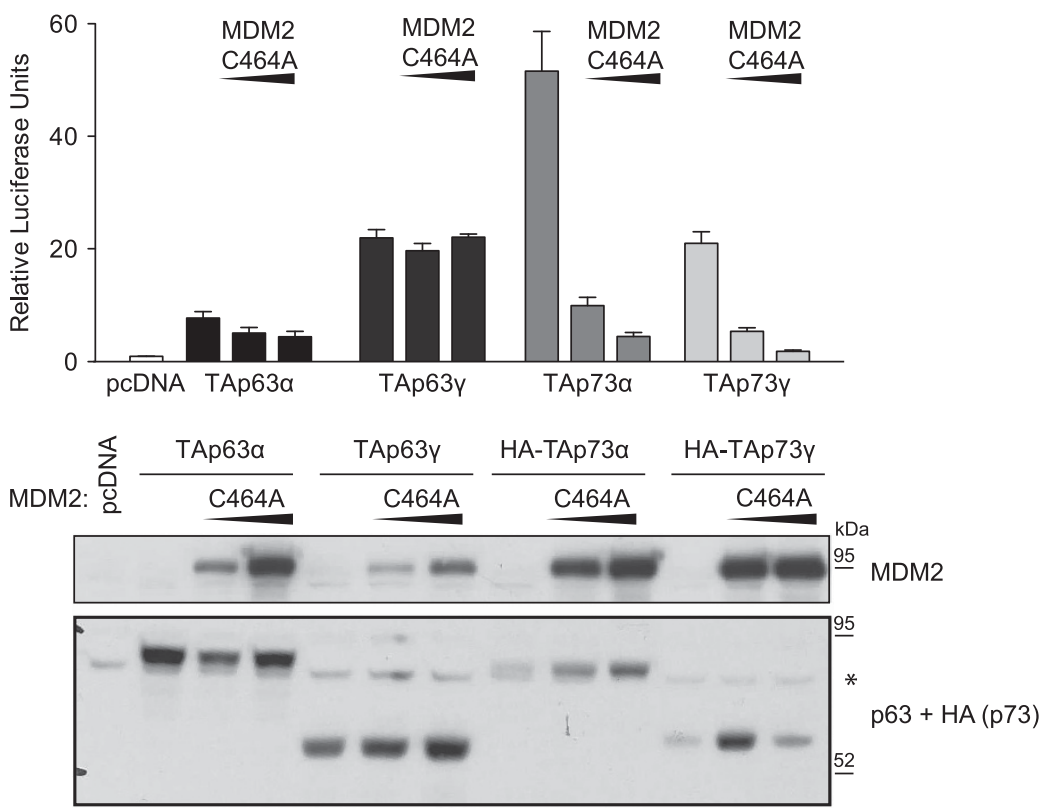

Figure 3. MDM2 binds and inhibits TA and $\Delta$ Np73 but not p63. (a) Immunoprecipitation of MDM2 (Ab1) in HCT116 p53 - / - cells transfected with $3 \mu \mathrm{g} \mathrm{HA}$-tagged TAp63 $\alpha, \Delta$ Np63 $\alpha$, TAp73 $\alpha$ (Simian) or $\Delta$ Np73 $\alpha$ in combination with $2 \mu \mathrm{g}$ MDM2 C464A. MDM2 and p63 or p73 expression was determined in the inputs and in precipitated material by western blot using the Ab1 (MDM2) and HA antibodies. (b) Immunoprecipitation of MDM2 (Ab1) in HCT116 p53-/ - cells transfected with $3 \mu \mathrm{g}$ HA-tagged TAp63 $\alpha, \Delta$ Np63 $\alpha$, TAp73 $\alpha$ or $\Delta$ Np73 $\alpha$ in combination with $2 \mu \mathrm{g}$ MDM2 $\Delta 58-89$ C464A. MDM2 and p63 or p73 expression was determined in the inputs and in precipitated material by western blot using the Ab1 (MDM2) and HA antibodies. (c) HCT116 p53-/ - cells were transfected with $300 \mathrm{ng}$ PG13 luciferase, $100 \mathrm{ng}$ TK Renilla and either $300 \mathrm{ng}$ empty vector or p53 together with increasing amounts of MDM2 C464A ( 25 and $100 \mathrm{ng}$ ). Activation of the promoters was assayed using the Promega Luciferase System. Data are plotted as relative luciferase units (RLU) (firefly luciferase readings divided by Renilla luciferase readings) fold change relative to p53-null control. The diagram represents the mean of triplicates with error bars as s.e.m. The expression of MDM2 and p53 was determined by western blot using Ab1 or DO-1 antibodies. (d) HCT116 p53 - / - cells were transfected with 300 ng BPAG luciferase, $100 \mathrm{ng}$ TK Renilla in combination with $300 \mathrm{ng}$ TAp63 $\alpha$, TAp63 $\gamma$, HA-TAp73 $\alpha$ or HA-TAp73 $\gamma$ and 0.2 or $0.5 \mu \mathrm{g}$ of MDM2 C464A and luciferase activity determined. Data are plotted as RLUs (firefly luciferase readings divided by Renilla luciferase readings) fold change relative to p53-null control. The diagram represents the mean of triplicates with error bars as s.e.m. The expression of MDM2 and p63 or p73 was determined by western blot using an Ab1 (MDM2) or BC4A4 (p63)+HA (p73). *A nonspecific band.

while potentiating mutant p53 binding and inhibition of TAp73a (Figure 5b).

\section{DISCUSSION}

p53, p63 and p73 are a family of related proteins with distinct but overlapping functions. Although each of these proteins can homo- oligomerize, wild-type p53 does not interact efficiently with either p63 or p73. By contrast, tumor-associated point mutations in the DBD of p53 can induce an ability of the mutant p53 to bind both p63 and p73, an activity that correlates with the acquisition of a misfolded conformation of the mutant p53 protein. Our results are in agreement with previous reports that have shown a contribution of the DBD of $p 73$ to the interaction with mutant $p 53 .{ }^{20}$ 
a

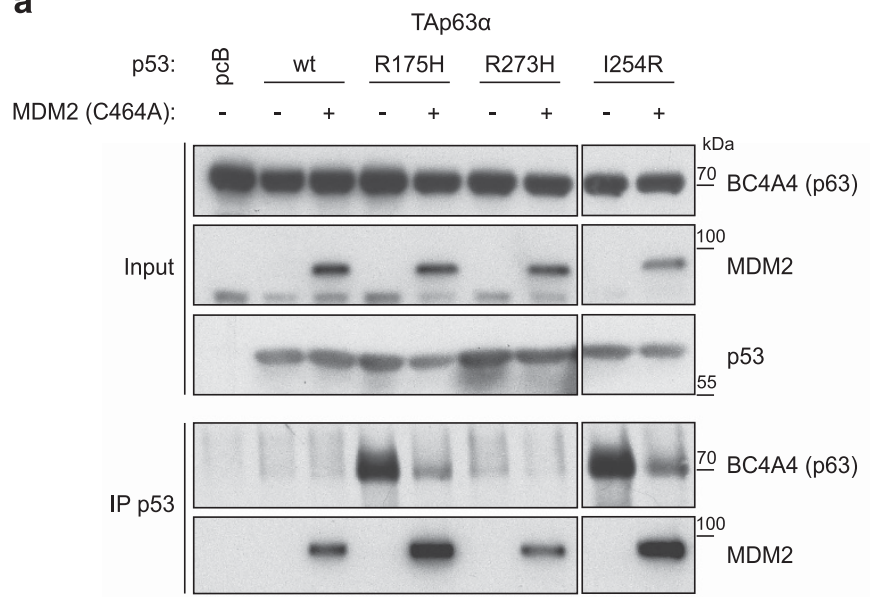

b
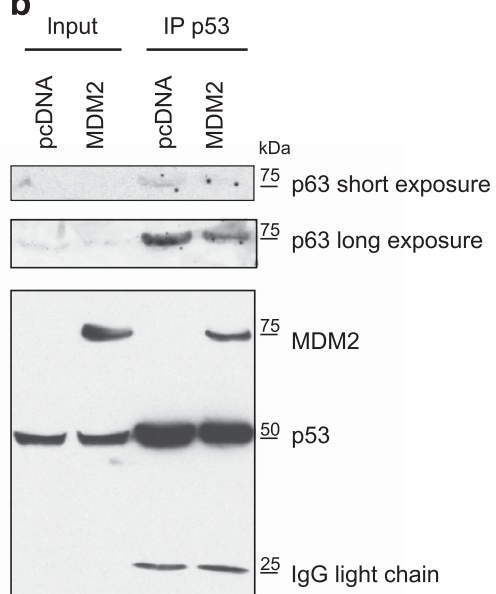

C

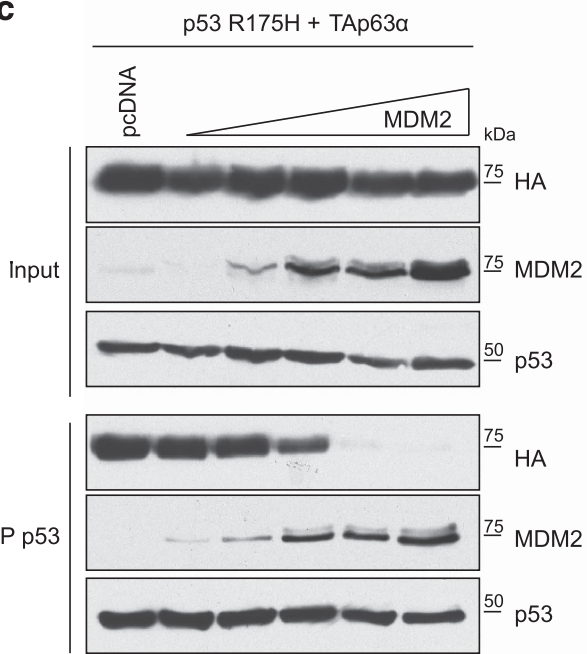

e

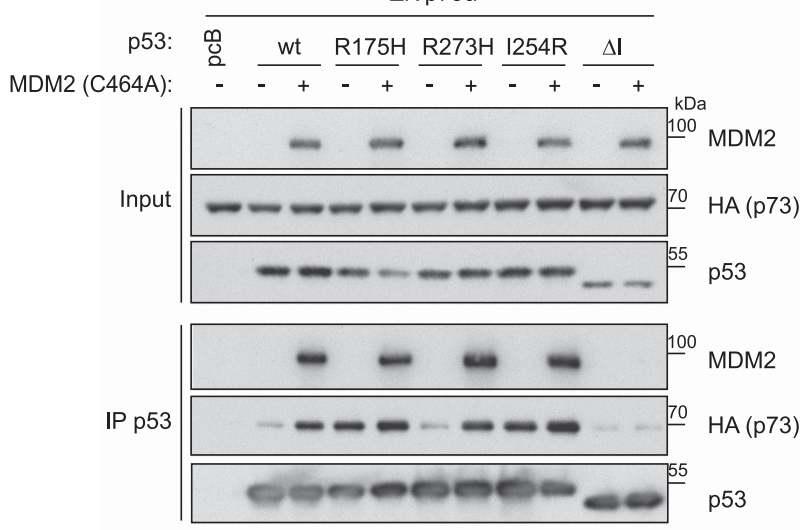

d

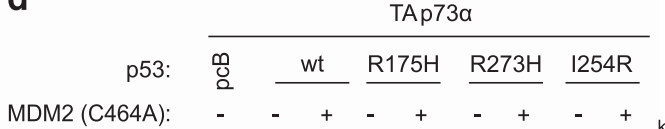

MDM2 (C464A): $\quad-\quad-+\ldots+-+\ldots+$
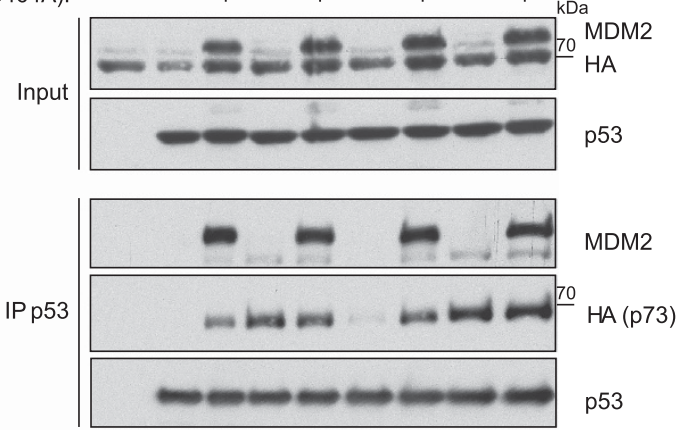

f

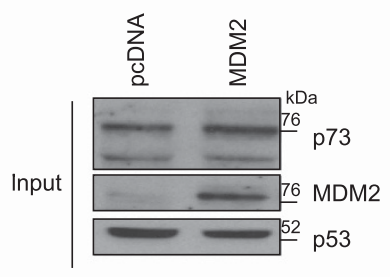

IP p53

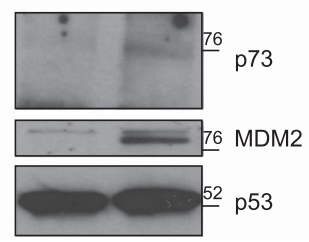

Figure 4. MDM2 competes for binding of mutant p53 with p63, but promotes the binding of mutant p53 with p73. (a) Immunoprecipitation of

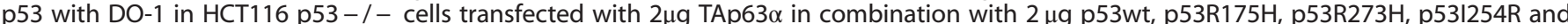
MDM2 C464A. P53, MDM2 and p63 expression was determined in the inputs and p63 and MDM2 expression was determined in precipitated material by western blot using DO-1, Ab1 (MDM2) and BC4A4 (p63) antibodies. (b) Immunoprecipitation of p53 with DO-1 in BXPC3 cells (three $10 \mathrm{~cm}$ plates) that were transfected with $3 \mu \mathrm{g}$ MDM2 C464A or pcDNA. MDM2, p63 and p53 expression was determined in inputs and immunoprecipitations by western blot using p53 DO-1, MDM2 SMP14 and p63 4A4 antibodies. (c) Immunoprecipitation of p53 using DO-1 in HCT116 - / - cells transfected with $3 \mu \mathrm{g} \mathrm{HA-TAp63 \alpha}$ and p53R175H each in combination with $0,0.5,1.0,2.0,4.0$ or $6.0 \mu \mathrm{g}$ MDM2 C464A or compensatory amounts of pcDNA. MDM2, p63 and p53 expression levels were determined in the input and precipitated material using western blot and SMP14, HA and DO-1 antibodies, respectively. (d and e) Immunoprecipitation of p53 with DO-1 (d) or 1801 (e) in HCT116 p53 - / - cells transfected with $2 \mu \mathrm{g} \mathrm{HA-TAp73 \alpha}$ (d) or HA- $\Delta$ Np73 $\alpha$ (e) in combination with $2 \mu \mathrm{g} \mathrm{p53wt,} \mathrm{p53R175H,} \mathrm{p53R273H,} \mathrm{p53I254R,} \mathrm{p53} \mathrm{I}$ (only in e) and MDM2 C464A. P53, MDM2 and p73 (HA) expression was determined in the inputs and in precipitated material by western blot using DO-1 (d), 1801 (e), Ab1 (MDM2) and HA antibodies. (f) Immunoprecipitation of p53 with DO-1 in U251 cells that were transfected with $3 \mu \mathrm{g}$ MDM2 C464A or pCDNA. MDM2, p73 and p53 expression was determined in inputs and immunoprecipitations by western blot using p53 DO-1, MDM2 SMP14 and a p73 antibody. 
a BPAG-1 Luciferase
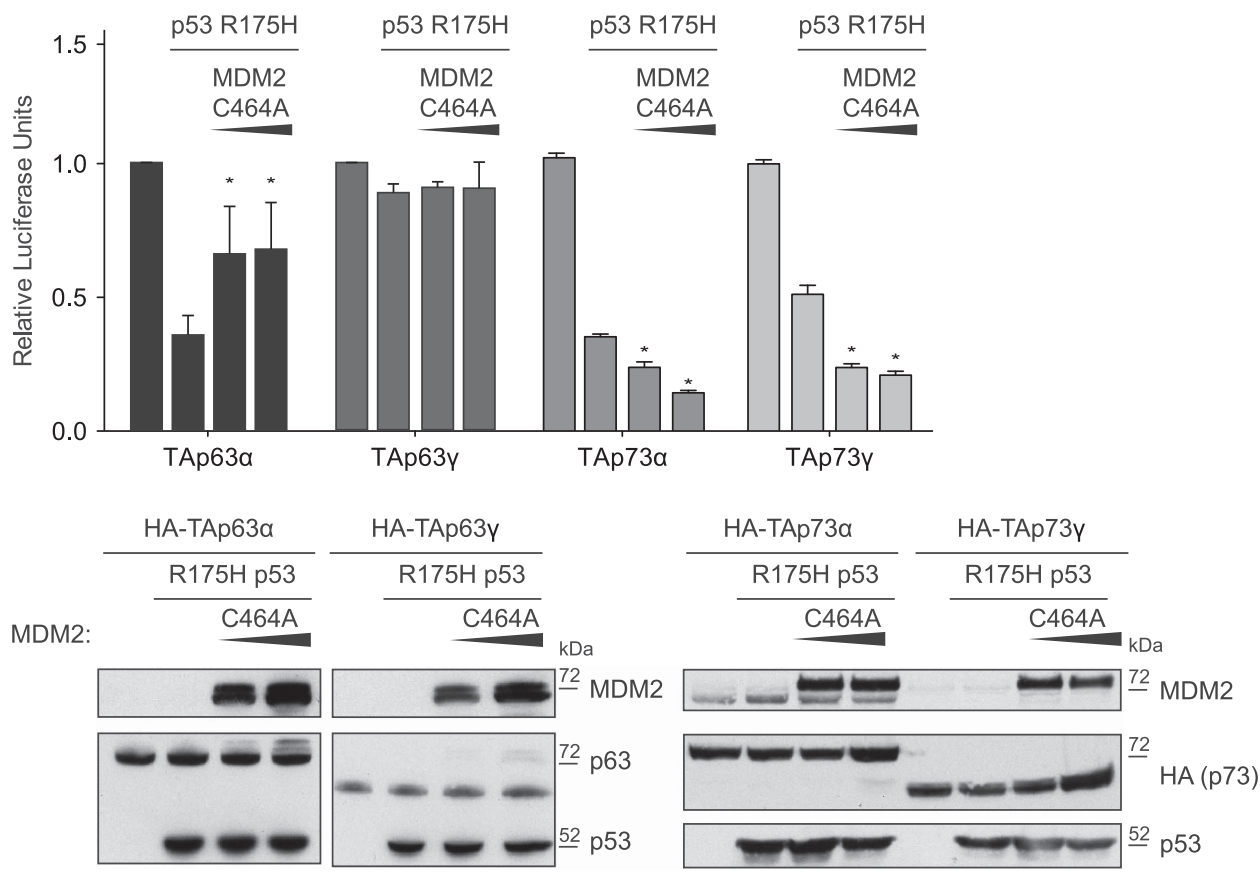

b
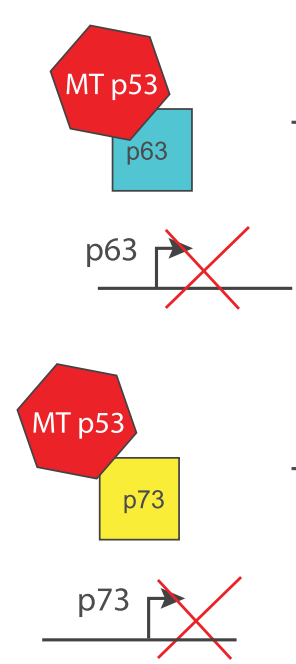
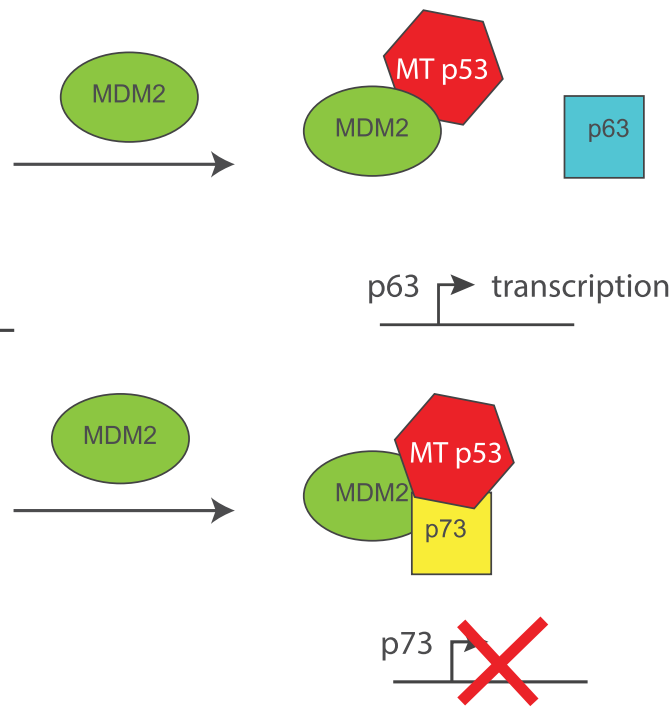

Figure 5. MDM2 prevents mutant p53 from inhibiting TAp63 $\alpha$, but potentiates the inhibition of TAp73. (a) HCT116 p53-/- cells were transfected with $300 \mathrm{ng}$ BPAG luciferase, $100 \mathrm{ng}$ TK Renilla, $2 \mu \mathrm{g}$ p53R175H and increasing concentrations $(0.2,0.4$ and $0.6 \mu \mathrm{g})$ of MDM2 C464A

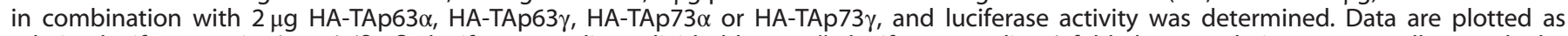
relative luciferase units (RLUs) (firefly luciferase readings divided by Renilla luciferase readings) fold change relative to p53-null control. The diagram represents the mean of triplicates with error bars as s.e.m. The expression of MDM2, p63, p73 and p53 was determined by western blot using Ab1 (MDM2), BC4A4 (p63), HA or DO-1 (p53). (b) Schematic representation of the consequences of MDM2 expression on the inhibitory function of mutant p53 on p63 or p73. Expression of MDM2 alleviates the inhibitory role of mutant p53 on p63, but potentiates the inhibition of $\mathrm{p} 73$ by mutant p53.

However, we also show that the $C$ termini of 063 and p73 have an important role in permitting this interaction. Intriguingly, although binding is decreased in TAp63 $\beta$, TAp63 $\gamma$ and TAp73 $\beta$, the novel amino acids at the $C$ terminus of TAp73 $\gamma$ reinstate the ability to bind mutant $\mathrm{p} 53$. These results present the interesting possibility that mutant p53 may differentially inhibit the C-terminal isoforms of TAp63 and TAp73. Indeed, our data support this suggestion, as we show that mutant $\mathrm{p} 53 \mathrm{R} 175 \mathrm{H}$ inhibits the transcriptional activity of TAp63a, but is unable to inhibit this function of TAp63y. However, the transcriptional activity of both TAp73a and TAp73 $\gamma$ is efficiently inhibited by mutant p53R175H (Figure 5). Given the pro-oncogenic role of mutant p53, this differential activity of mutant p53 may be important in tumor development.

Previous studies have shown that most mutant p53s can form aggregates in vitro and in cells, ${ }^{38,46}$ and that these can also include full-length and N-terminal truncated p63 and p73 isoforms. ${ }^{38} \mathrm{~A}$ 
single point mutation of isoleucine 254 in p53 was shown to prevent aggregation and interaction of $\mathrm{p} 53 \mathrm{R} 175 \mathrm{H}$ with TAp63 or TAp73. We show here, however, that the interaction of mutant p53 with TAp63 and TAp73 is not dependent on isoleucine 254. Instead, p53 carrying a substitution of this residue to arginine, which would disrupt aggregation, behaves like a tumor-derived DBD point mutant. Specifically, p531254R acquires the ability to react with a mutant-specific antibody, bind to TAp63a/TAp73a, inhibit TAp63a and promote invasion in a three-dimensional cell culture system. Indeed, I245R is found in the p53 database of somatic tumor mutations, albeit rarely $(0.2 \%$ of all recorded somatic p53 mutations), suggesting that this mutation can be advantageous during cancer development. ${ }^{47}$ Although the ability to form aggregates may contribute to the oncogenic activity of mutant p53, our data show that aggregation mediated through the previously identified domain within amino acids 251-257 of p53 is not required for mutant p53 to show oncogenic activities. Indeed, the ability of mutant p53 to regain wild-type p53 activity (e.g. with temperature-sensitive mutant $\mathrm{p} 53^{48}$ ) suggests that these mutants are not necessarily locked into irreversible aggregates. It seems that multiple mechanisms through which mutant p53 can inhibit p63/p73 functions exist, including the direct binding (as described here) and mechanisms that do not depend on tight and stable complex formation, as exhibited by p53 mutants such as $\mathrm{R} 273 \mathrm{H}^{23}$

One of the key regulators of p53 function is MDM2, which also binds to mutant $\mathrm{p} 53$ through the $\mathrm{N}$-terminal binding regions in both proteins. MDM2 can promote the degradation of mutant $\mathrm{p} 53,{ }^{49,50}$ although in tumor cells this regulation is disrupted, for example, through the expression of MDM2 isoforms that inhibit full-length MDM2 E3 ligase activity, ${ }^{51}$ and mutant p53 protein accumulates. In agreement with previous results, ${ }^{34,42}$ we can detect MDM2 binding to TAp73a and $\triangle N p 73 a$, but to a much lesser extent to TAp63a and $\triangle \mathrm{Np} 63 \mathrm{a}$ in cells. This differential binding is reflected by a far superior inhibition of TAp73a and $\triangle \mathrm{Np73a}$ transcriptional activity by MDM2, which has almost no effect on TAp63a and $\triangle N p 63 a$ transcriptional activity in these assays. These data support in vitro studies showing that TAp63 can bind MDM2 with a much lower affinity than p53 or TAp73. ${ }^{52}$ As with the binding of mutant $\mathrm{p} 53$, these observations suggest that there are significant differences in the ability of both N-terminal variants of $\mathrm{p} 63$ and p73 to interact with protein binding partners. Interestingly, this differential ability to bind MDM2 is reflected by different consequences of MDM2 on the mutant p53 interaction with p63 or p73. We find that while MDM2 can inhibit the p53R175H/TAp63a interaction-suggesting competition between MDM2 and TAp63a for binding to mutant p53-MDM2 can enhance the interaction of $\mathrm{p} 53 \mathrm{R} 273 \mathrm{H}$ with TAp73a or $\Delta \mathrm{Np} 73 \mathrm{a}$. This latter effect is seen most clearly using mutants of p53 that do not strongly activate p73 binding (such as R273H), whereas the interaction of strongly binding mutant p53 (such as $\mathrm{R} 175 \mathrm{H}$ ) are unaffected by MDM2. MDM2 is not the only protein that can form a complex with p53 family members, and a recent publication has suggested that HSP70 shows a similar differential effect of reactivating $\mathrm{p} 63$, but not $\mathrm{p} 73$, in the presence of mutant $\mathrm{p} 53 .{ }^{45}$ In addition to HSP70 and MDM2, a number of other proteins could affect mutant p53/p63/p73 interactions, including HSP90, the CCT (chaperonin containing tailless complex polypeptide 1) complex, HAUSP (herpesvirus-associated ubiquitin-specific protease) or CHIP (C-terminus of Hsc70-interacting protein). Additional complexity is provided by the potential for expression of many isoforms of all the p53 family proteins. ${ }^{9,53}$

In this study, we have focused on the consequences of MDM2 expression on mutant $\mathrm{p} 53 / \mathrm{p} 63$ and $\mathrm{p} 73$ interactions. We showed that MDM2 relieves the inhibition of p63 activity by mutant p53, but can enhance the inhibition of p73 by mutant $p 53$. Although the impact of other interacting proteins remains to be addressed, our observations point to an interesting differential ability of MDM2 to regulate the activity of mutant p53.

\section{MATERIALS AND METHODS}

Cells

H1299 and HEK293T cells (obtained from American Type Culture Collection, Teddington, UK) and HCT116 p53-null cells (a gift from Dr Bert Vogelstein) were maintained in DMEM (Life Technologies, Paisley, UK) supplemented with $10 \%$ fetal bovine serum, $1 \%$ pen/strep and $1 \%$ glutamine at $37^{\circ} \mathrm{C}$ in $5 \% \mathrm{CO}_{2}$.

\section{Plasmids}

The following plasmids have been previously described: pcDNA constructs-HA-TAp63a, HA- $\triangle$ Np63a, HA-TAp73a, HA- $\Delta$ Np73a, TAp63a, TAp63ß, TAp63y, $\Delta$ Np63a, $\Delta$ Np63y, TAp63aFWL, Myc-p63a and Mycp63aFWL; ${ }^{13,54-57}$ pcB6 constructs-p53 wild type, p53R175H, p53R273H amd $\mathrm{p} 53 \Delta \mathrm{l}^{58}$ and PCHDM1A constructs-MDM2, MDM2 $\triangle 58-89$ and MDM2 C464, ${ }^{59,60}$ BPAG luciferase and PG13 luciferase, ${ }^{61,62}$ Myc-TAp63a and Myc-TAp63a FWL ${ }^{13}$ and pWZL blast p53. ${ }^{63}$

The following constructs were generated by site-directed mutagenesis: pcDNA3 constructs-p53R175H, p53I254R, p53R248W, p53R273H, p53R175H $\triangle 251-312$, p53R175H $\triangle 251-257$, p53R175H I254R, HA-TAp63a $\Delta$ 263-361, HA-TAp63a $\Delta 362-461$, HA-TAp63a $\triangle 462-561$, HA-TAp63a

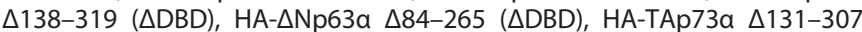
$(\triangle \mathrm{DBD}), \mathrm{HA}-\mathrm{TAp} 73 \mathrm{a} \Delta 308-386$ ( $\triangle \mathrm{DBD})$, pWZL blast p53R175H, pWZL blast p53R273H, pWZL blast p531254R, pWZL blast p53R248W and pCHDM1A MDM2 $\triangle 58-89$ C464A. Oligonucleotides used for site-directed mutagenesis are listed in the Supplementary Information. HA-tagged p63 $\beta$ and p63y were generated using site-directed mutagenesis in the non-tagged constructs provided by Dr Caron de Fromentel.

\section{Immunoprecipitation and immunoblot}

A total of $7.5 \times 10^{5}$ cells were seeded in $10 \mathrm{~cm}$ plates and transfected with 3-6 $\mu \mathrm{g}$ DNA the following day using 15-18 $\mu$ l GeneJuice in $300 \mu \mathrm{l} \mathrm{Opti-}$ Mem (Life Technologies). The transfection mix was added to the plates dropwise and cells were harvested 20-24 h later in RIPA buffer $(50 \mathrm{mM}$ Tris, $\mathrm{pH} 7.4,150 \mathrm{~mm} \mathrm{NaCl}, 1 \%$ Triton, $0.5 \%$ deoxycholate, $0.1 \%$ sodium dodecyl sulfate). Lysates were incubated for $15 \mathrm{~min}$ on ice and the supernatant was taken for immunoprecipitation with the indicated antibodies $(0.5-2 \mu \mathrm{g}$ per sample) overnight at $4{ }^{\circ} \mathrm{C}$ using protein $\mathrm{G}$ magnetic beads (Dynabeads; Invitrogen, Life Technologies). The following antibodies were used for immunoprecipitation: p53 DO-1 (Santa Cruz, Santa Cruz, CA, USA), p53 pAb1620 (Calbiochem, Nottingham, UK), p53 pAb240 (Calbiochem), HA (Covance, Leeds, UK) and MDM2 Ab1 (Calbiochem). Input and precipitates were run on western page and the following first antibodies were used p53 DO-1, p63 BC4A4 (Santa Cruz), p63 4A4 (Santa Cruz), p73, ${ }^{29}$ p73 Ab 7824 (Millipore, Watford, UK), HA (Covance), actin C4 (Chemicon), HSP70 (Enzo, Life Sciences, Exeter, UK), Ab1 MDM2 (Calbiochem), MDM2 SMP14 (Santa Cruz) or Myc (9E10; Covance). For immunoprecipitations, a rat antimouse IgK light-chain horse radish peroxidase (BD Biosciences, Oxford, UK) was used and all other detections were carried out with regular mouse or rabbit horse radish peroxidase-coupled Amersham secondary antibodies (GE Healthcare Life Sciences, Little Chalfont, UK).

\section{Luciferase assays}

Cells were seeded to $70 \%$ confluency into 24 wells for transfection using GeneJuice (25 or $100 \mathrm{ng}$ p53 constructs, $50 \mathrm{ng}$ p63 or p73, $50 \mathrm{ng}$ MDM2, $25 \mathrm{ng}$ Renilla, $100 \mathrm{ng}$ BPAG luciferase). At $24 \mathrm{~h}$ after transfection, cells were lysed in $100 \mu \mathrm{l}$ lysis buffer using a Renilla Luciferase Kit according to the manufacturer's protocol (Promega, Southampton, UK). Luciferase and Renilla activity was measured using a Veritas Microplate luminometer (Turner Biosystems, Promega) and the Glomax software from Promega. Relative luciferase units were determined by correcting luciferase readings for Renilla luciferase expression. Error bars represent the s.e.m. for three independent experiments. Of each lysate, $20 \mu \mathrm{l}$ was run on the immunoblot to test the expression of the transfected constructs.

\section{Matrigel invasion}

H1299 cells were retrovirally infected with empty vector or p53 mutants using HEK293T cells as packaging cells and were subsequently selected 
with $7.5 \mu \mathrm{g} / \mathrm{ml}$ blasticidin for 3-4 days. In Transwell inserts $(6.5 \mathrm{~mm}, 8 \mu \mathrm{m}$ pore size; Corning Life Sciences, High Wycombe, UK) in a 24-well plate $60 \mu \mathrm{l}$ Matrigel batch A6520 (BD Bioscience) diluted 1:1 in phosphatebuffered saline, containing $25 \mathrm{ng} / \mathrm{ml}$ fibronectin was pipetted carefully onto the center of the membrane and incubated $45 \mathrm{~min}$ at $37^{\circ} \mathrm{C}$. The inserts were inverted on the lid of a 24 -well plate and $100 \mu \mathrm{l}$ of a $2.5 \times 10^{5}$ cells per $\mathrm{ml}$ cell suspension was pipetted onto the membrane, whereafter the 24-well plate was fitted over the inserts to create 'hanging droplets' of cells. Cells were allowed to settle for $5 \mathrm{~h}$ at $37^{\circ} \mathrm{C}$, whereafter the transwells were washed in serum-free medium and transferred (upright) to a 24-well plate containing $1 \mathrm{ml}$ serum-free medium. One hundred microliters of medium containing serum and $10 \mathrm{ng} / \mathrm{ml}$ hepatocyte growth factor was pipetted into the center of the insert on top of the polymerized Matrigel to attract cells from above the Matrigel plug. Cells were allowed to migrate for 3 days and stained in the medium containing $4 \mathrm{~nm}$ calcein (Life Technologies) for $1 \mathrm{~h}$. Migration was visualized on a Leica TCS SP2 laser scanning confocal microscope (Leica, Peterborough, UK), taking images in serial sections every $15 \mu \mathrm{m}$ starting at the membrane and moving up into the Matrigel plug until no more cells could be detected. The number of pixels with intensity of 100 or above was quantified in each binary confocal image using ImageJ. ${ }^{64}$ The percentage of invading cells was calculated by dividing the sum of pixels at or beyond $45 \mu \mathrm{m}$ by the sum of pixels in all images.

\section{CONFLICT OF INTEREST}

The authors declare no conflict of interest.

\section{ACKNOWLEDGEMENTS}

We thank Drs Gerry Melino, Caron de Fromentel and Kevin Ryan for plasmids and are grateful to Cancer Research UK, the DFG (DO 545/8-1), The Wellcome Trust/the Royal Society (Sir Henry Dale Fellowship) and the Cluster of Excellence Frankfurt (Macromolecular Complexes) for funding.

\section{REFERENCES}

1 Vousden $\mathrm{KH}$, Prives C. Blinded by the light: the growing complexity of p53. Cell 2009; 137: 413-431.

2 Hollstein M, Sidransky D, Vogelstein B, Harris CC. P53 mutations in human cancers. Science (New York) NY 1991; 253: 49-53.

3 Kato S, Han SY, Liu W, Otsuka K, Shibata H, Kanamaru R et al. Understanding the function-structure and function-mutation relationships of p53 tumor suppressor protein by high-resolution missense mutation analysis. Proc Natl Acad Sci USA 2003; 100: 8424-8429.

4 Rivlin N, Brosh R, Oren M, Rotter V. Mutations in the p53 tumor suppressor gene: important milestones at the various steps of tumorigenesis. Genes Cancer 2011; 2: 466-474.

5 Muller PA, Vousden KH. P53 mutations in cancer. Nat Cell Biol 2013; 15: 2-8.

6 Yang A, Kaghad M, Wang Y, Gillett E, Fleming MD, Dotsch V et al. P63, a p53 homolog at 3q27-29, encodes multiple products withtransactivating, deathinducing, and dominant-negative activities. Mol Cell 1998; 3: 305-316.

7 Kaghad M, Bonnet H, Yang A, Creancier L, Biscan J-C, Valent A et al. Monoallelically expressed gene related to $\mathrm{p} 53$ at $1 \mathrm{p} 36$, a region frequently deleted in neuroblastoma and other human cancers. Cell 1997; 90: 809-819.

8 Ishimoto O, Kawahara C, Enjo K, Obinata M, Nukiwa T, Ikawa S. Possible oncogenic potential of DeltaNp73: a newly identified isoform of human p73. Cancer Res 2002; 62: 636-641.

9 Khoury MP, Bourdon JC. The isoforms of the p53 protein. Cold Spring Harb Perspect Biol 2010; 2: a000927.

10 Natan $E$, Joerger AC. Structure and kinetic stability of the p63 tetramerization domain. J Mol Biol 2012; 415: 503-513.

11 Ethayathulla AS, Tse PW, Monti P, Nguyen S, Inga A, Fronza G et al. Structure of p73 DNA-binding domain tetramer modulates p73 transactivation. Proc Natl Acad Sci USA 2012; 109: 6066-6071.

12 Straub WE, Weber TA, Schafer B, Candi E, Durst F, Ou HD et al. The C-terminus of p63 contains multiple regulatory elements with different functions. Cell Death Dis 2010; 1: e5.

13 Deutsch GB, Zielonka EM, Coutandin D, Weber TA, Schafer B, Hannewald J et al. DNA damage in oocytes induces a switch of the quality control factor TAp63alpha from dimer to tetramer. Cell 2011; 144: 566-576.

14 Luh LM, Kehrloesser S, Deutsch GB, Gebel J, Coutandin D, Schafer B et al. Analysis of the oligomeric state and transactivation potential of TAp73alpha. Cell Death Differ 2013; 20: 1008-1016.
15 Coutandin D, Lohr F, Niesen FH, Ikeya T, Weber TA, Schafer B et al. Conformational stability and activity of p73 require a second helix in the tetramerization domain. Cell Death Differ 2009; 16: 1582-1589.

16 Joerger AC, Rajagopalan S, Natan E, Veprintsev DB, Robinson CV, Fersht AR. Structural evolution of p53, p63, and p73: implication for heterotetramer formation. Proc Natl Acad Sci USA 2009; 106: 17705-17710.

17 Di Como CJ, Gaiddon C, Prives C. P73 function is inhibited by tumor-derived p53 mutants in mammalian cells. Mol Cell Biol 1999; 19: 1438-1449.

18 Gaiddon C, Lokshn M, Ahn J, Zhang T, Prives C. A subset of tumor-derived mutant forms of p53 down-regulate p63 and p73 through a direct interaction with the p53 core domain. Mol Cell Biol 2001; 21: 1874-1887.

19 Strano S, Fontemaggi G, Costanzo A, Rizzo MG, Monti O, Baccarini A et al. Physical interaction with human tumor derived p53 mutants inhibits p63 activities. J Biol Chem 2002; 277: 18817-18826.

20 Strano S, Munarriz E, Rossi M, Cristofanellu B, Shaul Y, Castagnoli L et al. Physical and functional interaction between p53 mutants and difference isoforms of p73. J Biol Chem 2000; 275: 29503-29512.

21 Santini S, Di Agostino S, Coppari E, Bizzarri AR, Blandino G, Cannistraro S. Interaction of mutant p53 with p73: asurface plasmon resonance and atomic force spectroscopy study. Biochim Biophys Acta 2014; 1840: 1958-1964.

22 Adorno M, Cordenonsi M, Montagner M, Dupont S, Wong C, Hann B et al. A mutant-p53/Smad complex opposes p63 to empower TGFbeta-induced metastasis. Cell 2009; 137: 87-98.

23 Muller PA, Caswell PT, Doyle B, Iwanicki MP, Tan EH, Karim S et al. Mutant p53 drives invasion by promoting integrin recycling. Cell 2009; 139: 1327-1341.

24 Neilsen PM, Noll JE, Suetani RJ, Schulz RB, Al-Ejeh F, Evdokiou A et al. Mutant p53 uses p63 as a molecular chaperone to alter gene expression and induce a proinvasive secretome. Oncotarget 2011; 2: 1203-1217.

25 Kubbutat MHG, Jones SN, Vousden KH. Regulation of p53 stability by Mdm2. Nature 1997; 387: 299-303.

26 Haupt Y, Maya R, Kazaz A, Oren M. Mdm2 promotes the rapid degradation of p53. Nature 1997; 387: 296-299.

27 Momand J, Zambetti GP, George DL, Levine AJ. The mdm-2 oncogene product forms a complex with the $\mathrm{p} 53$ protein and inhibits p53-mediated transactivation. Cell 1992; 69: 1237-1245.

28 Oliner JD, Pietenpol JA, Thiagalingam S, Gyuris J, Kinzler KW, Vogelstein B. Oncoprotein MDM2 conceals the activation domain of tumour suppressor p53. Nature 1993; 362: 857-860.

29 Balint $\mathrm{E}$, Bates $\mathrm{S}$, Vousden $\mathrm{KH}$. Mdm2 binds p73a without targeting degradation. Oncogene 1999; 18: 3923-3929.

30 Zeng X, Chen L, Jost CA, Maya R, Keller D, Wang X et al. MDM2 suppresses p73 function without promoting p73 degradation. Mol Cell Biol 1999; 19: 3257-3266.

31 Dobbelstein M, Wienzek S, Koenig S, Roth J. Inactivation of the p53-homologue p73 by the mdm2-oncoprotein. Oncogene 1999; 18: 2101-2106.

32 Kadakia M, Slader C, Berberich SJ. Regulation of p63 function by Mdm2 and MdmX. DNA Cell Biol 2001; 20: 321-330.

33 Calabro V, Mansueto G, Parisi T, Vivo M, Calogero RA, La Mantia G. The human MDM2 oncoprotein increases the transcriptional activity and the protein level of the p53 homolog p63. J Biol Chem 2002; 277: 2674-2681.

34 Little NA, Jochemsen AG. Hdmx and Mdm2 can repress transcription activation by p53 but not by p63. Oncogene 2001; 20: 4576-4580.

35 Kojima T, Ikawa Y, Katoh I. Analysis of molecular interactions of the p53-family p51 (p63) gene products in a yeast two-hybrid system: homotypic and heterotypic interactions and association with p53-regulatory factors. Biochem Biophys Res Commun 2001; 281: 1170-1175.

36 Joerger AC, Fersht AR. Structure-function-rescue: the diverse nature of common p53 cancer mutants. Oncogene 2007; 26: 2226-2242.

37 Serber Z, Lai HC, Yang A, Ou HD, Sigal MS, Kelly AE et al. A C-terminal inhibitory domain controls the activity of $\mathrm{p} 63$ by an intramolecular mechanism. Mol Cell Biol 2002; 22: 8601-8611.

$38 \mathrm{Xu}$ J, Reumers J, Couceiro JR, De Smet F, Gallardo R, Rudyak S et al. Gain of function of mutant $\mathrm{p} 53$ by coaggregation with multiple tumor suppressors. Nat Chem Biol 2011; 7: 285-295.

39 Gannon JV, Greaves R, Iggo R, Lane DP. Activating mutations in p53 produce a common conformational effect. A monoclonal antibody specific for the mutant form. EMBO J 1990; 9: 1595-1602.

40 Joerger AC, Fersht AR. Structural biology of the tumor suppressor p53 and cancerassociated mutants. Adv Cancer Res 2007; 97: 1-23.

41 Trinidad AG, Muller PA, Cuellar J, Klejnot M, Nobis M, Valpuesta JM et al. Interaction of p53 with the CCT complex promotes protein folding and wild-type p53 activity. Mol Cell 2013; 50: 805-817.

42 Wang X, Arooz T, Siu WY, Chiu CH, Lau A, Yamashita K et al. MDM2 and MDMX can interact differently with ARF and members of the p53 family. FEBS Lett 2001; 490: 202-208. 
43 Li D, Marchenko ND, Schulz R, Fischer V, Velasco-Hernandez T, Talos F et al. Functional inactivation of endogenous MDM2 and CHIP by HSP90 causes aberrant stabilization of mutant p53 in human cancer cells. Mol Cancer Res 2011; 9: 577-588.

44 Muller P, Hrstka R, Coomber D, Lane DP, Vojtesek B. Chaperone-dependent stabilization and degradation of p53 mutants. Oncogene 2008; 27: 3371-3383.

45 Wiech M, Olszewski MB, Tracz-Gaszewska Z, Wawrzynow B, Zylicz M, Zylicz A. Molecular mechanism of mutant p53 stabilization: the role of HSP70 and MDM2. PLoS One 2012; 7: e51426.

46 Ano Bom AP, Rangel LP, Costa DC, de Oliveira GA, Sanches D, Braga CA et al. Mutant p53 aggregates into prion-like amyloid oligomers and fibrils: implications for cancer. J Biol Chem 2012; 287: 28152-28162.

47 Petitjean A, Mathe E, Kato S, Ishioka C, Tavtigian SV, Hainaut P et al. Impact of mutant p53 functional properties on TP53 mutation patterns and tumor phenotype: lessons from recent developments in the IARC TP53 database. Hum Mutat 2007; 28: 622-629.

48 Michalovitz D, Halevy O, Oren M. Conditional inhibition of transformation and of cell proliferation by a temperature-sensitive mutant of p53. Cell 1990; 62 671-680.

49 Midgley CA, Lane DP. P53 protein stability in tumour cells is not determined by mutation but is dependent on Mdm2 binding. Oncogene 1997; 15: 1179-1189.

50 Terzian T, Suh YA, Iwakuma T, Post SM, Neumann M, Lang GA et al. The inherent instability of mutant p53 is alleviated by Mdm2 or p16INK4a loss. Genes Dev 2008; 22: $1337-1344$

51 Zheng T, Wang J, Zhao Y, Zhang C, Lin M, Wang X et al. Spliced MDM2 isoforms promote mutant p53 accumulation and gain-of-function in tumorigenesis. Nat Commun 2013; 4: 2996.

52 Zdzalik M, Pustelny K, Kedracka-Krok S, Huben K, Pecak A, Wladyka B et al. Interaction of regulators Mdm2 and Mdmx with transcription factors p53, p63 and p73. Cell Cycle (Georgetown, TX 2010; 9: 4584-4591.

53 Dotsch V, Bernassola F, Coutandin D, Candi E, Melino G. P63 and p73, the ancestors of p53. Cold Spring Harb Perspect Biol 2010; 2: a004887.

54 De Laurenzi V, Costanzo A, Barcaroli D, Terrinoni M, Falco M, AnnicchiaricoPetruzzelli $M$ et al. Two new p73 splice variants, gamma and delta, with different transcriptional activity. J Exp Med 1998; 188: 1763-1768.

55 Petitjean A, Ruptier C, Tribollet V, Hautefeuille A, Chardon F, Cavard C et al. Properties of the six isoforms of p63: p53-like regulation in response to genotoxic stress and cross talk with DeltaNp73. Carcinogenesis 2008; 29: 273-281.

56 De Laurenzi V, Rossi A, Terrinoni A, Barcaroli D, Levrero M, Costanzo A et al. P63 and p73 transactivate differentiation gene promoters in human keratinocytes. Biochem Biophys Res Commun 2000; 273: 342-346.

57 Candi E, Rufini A, Terrinoni A, Dinsdale D, Ranalli M, Paradisi A et al. Differentia roles of $\mathrm{p} 63$ isoforms in epidermal development: selective genetic complementation in p63 null mice. Cell Death Differen 2006; 13: 1037-1047.

58 Lukashchuk N, Vousden $\mathrm{KH}$. Ubiquitination and degradation of mutant p53. Mol Cell Biol 2007; 27: 8284-8295.

59 Chen JD, Marechal V, Levine AJ. Mapping of the p53 and mdm-2 interaction domains. Mol Cell Biol 1993; 13: 4107-4114.

60 Kubbutat MHG, Ludwig RL, Levine AJ, Vousden KH. Analysis of the degradation function of Mdm2. Cell Growth Differ 1999; 10: 87-92.

61 Osada M, Nagakawa Y, Park HL, Yamashita K, Wu G, Kim MS et al. P63-specific activation of the BPAG-1e promoter. J Invest Dermatol 2005; 125: 52-60.

62 El-Deiry W, Tokino T, Velculescu VE, Levy DB, Parson VE, Trent JM et al. WAF1, a potential mediator of p53 tumour suppression. Cell 1993; 75: 817-825.

63 Stindt MH, Carter S, Vigneron AM, Ryan KM, Vousden KH. MDM2 promotes SUMO-2/3 modification of p53 to modulate transcriptional activity. Cell Cycle (Georgetown, TX) 2011; 10: 3176-3188.

64 Collins TJ. Image J for microscopy. Biotechniques 2007; 43: 25-30.

(c) (1) This work is licensed under a Creative Commons AttributionCon ${ }_{\mathrm{BY}}$ SA $\mathrm{SA}$ Nommercial-ShareAlike 4.0 International License. The images or other third party material in this article are included in the article's Creative Commons license, unless indicated otherwise in the credit line; if the material is not included under the Creative Commons license, users will need to obtain permission from the license holder to reproduce the material. To view a copy of this license, visit http:// creativecommons.org/licenses/by-nc-sa/4.0/

Supplementary Information accompanies this paper on the Oncogene website (http://www.nature.com/onc) 